\title{
Deuterium-Tritium Simulations of the Enhanced Reversed Shear Mode in the Tokamak Fusion Test Reactor
}

\author{
D. R. Mikkelsen, J. Manickam, S. D. Scott, and M. C. Zarnstorff \\ Princeton Plasma Physics Laboratory \\ P.O. Box 451, Princeton, NJ 08543
}

\begin{abstract}
The potential performance, in denterium-tritium plasmas, of a new enhanced confinement regime with reversed magnetic shear (ERS mode) is assessed. The equilibrium conditions for an ERS mode plasma are estimated by solving the plasma transport equations using the thermal and particle diffusivities measured in a short duration ERS mode discharge in the Tokamak Fusion Test Reactor [F. M. Levinton, et al., Phys. Rev. Letters, 75, 4417, (1995)]. The plasma performance depends strongly on $Z_{\text {eff }}$ and neutral beam penetration to the core. The steady state projections typically have a central electron density of $\sim 2.5 \times 10^{20} \mathrm{~m}^{-3}$ and nearly equal central electron and ion temperatures of $\sim 10 \mathrm{keV}$. In time dependent simulations the peak fusion power, $\sim 25 \mathrm{MW}$, is twice the steady state level. Peak performance occurs during the density rise when the central ion temperature is close to the optimal value of $\sim 15 \mathrm{keV}$. The simulated pressure profiles can be stable to ideal MHD instabilities with toroidal mode number $n=1,2,3,4$ and $\infty$ for $\beta_{\text {norm }}$ up to 2.5 ; the simulations have $\beta_{\text {norm }} \leq 2.1$. The enhanced reversed shear mode may thus provide an opportunity to conduct alpha physics experiments in conditions similar to those proposed for advanced tokamak reactors.

PACS categories: 52.55.Dy, 52.55.Fa, 52.55.Pi, 52.65.-y
\end{abstract}

\section{DISCLAIMER}

This report was prepared as an account of work sponsored by an agency of the United States Government. Neither the United States Gnvernment nor any agency thereof, nor any of their employees, makes any warranty, express or implied, or assumes any legal liability or responsibility for the accuracy, completeness, or usefulness of any information, apparatus, product, or process disclosed, or represents that its use would not infringe privately owned rights. Reference herein to any specific commercial product, process, or service by trade name, trademark, manufacturer, or otherwise does not necessarily constitute or imply its endorsement, recommendation, or favoring by the United States Government or any agency thereof. The views and opinions of authors expressed herein do not necessarily state or reflect those of the United States Government or any agency thereor.

\section{IITMBUTION OF THIS DOCUMENT IS UNLMT}

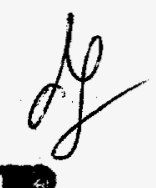




\section{DISCLAIMER}

Portions of this document may be illegible in electronic image products. Images are produced from the best available original document. 


\section{INTRODUCTION}

Theoretical studies show that reversed magnetic shear could play a key role in advanced tokamaks by simultaneously improving magnetohydrodynamic (MHD) stability, bootstrap current alignment, and confinement [1-3]. This is supported by a number of experiments in which reversed shear is linked to observed improvements in confinement and stability [4-8] The importance of magnetic shear reversal in future tokamaks motivated recent experiments which found a regime of greatly enhanced core confinement in the Tokamak Fusion Test Reactor (TFTR) [6,9]. Similar experiments in DIII-D [7,10,11], JT-60U [8,12], and JET [13] have also found regions of enhanced confinement associated with shear reversal.

The TFTR enhanced reversed shear (ERS) mode discharges exhibit two morphologies, which are referred to as type I and II. The most prominent distinguishing features are the more rapid central density rise in type I, and the more dramatic central electron temperature rise in type II. The discharge which provides the basis of this paper was selected because it has the longest duration of ERS mode with high power heating. This discharge is of type I and the particle and ion thermal diffusivities become remarkably low within the reversed shear region [6,9], approximately $r \leq 0.35 a$ (Fig. 1); the electron thermal diffusivity is not reduced during the ERS mode. The particle and ion thermal diffusivities are near or below standard neoclassical predictions. However, corrections to standard neoclassical theory such as orbit squeezing [14] may reduce the neoclassical transport predictions. A broader re-derivation of neoclassical theory based on realistic finite orbit width dynamics finds a strong reduction in neoclassically predicted ion thermal transport [15]; the new prediction is consistent with the experimental transport analysis. Transport outside $r \sim a / 2$ appears similar to the supershot regime $[6,9]$.

In TFTR ERS mode discharges the plasma density and temperatures have not reached equilibrium with the highest heating powers: either a disruption terminates the discharge, or the heating power is reduced before equilibrium is established. Theoretical work (and circumstantial experimental evidence) suggests that the evolution of $q(r)$ plays an important role in destabilizing these plasmas. Modifications of the $q$ profile are used to avoid disruptions. Modest changes have been achieved by altering the inductively prepared current distribution. Planned current drive systems will be used, when they become available, to further extend the period of stability. Disruption avoidance and near steady state have been achieved by reducing the beam power to a level which is sufficient to maintain an elevated core density; this may also be useful in prolonging high fusion power discharges.

The ERS mode projections reported here are estimates of the plasma conditions expected in deuterium-tritium (DT) discharges of sufficient duration to approach transport equilibrium. The simulations are based on the particle and thermal diffusivities measured in a deuterium TFTR discharge in the type I ERS regime (discharge parameters are given in Table I). The neutral beam deposition, alpha heating, and bremsstrahlung radiation in the simulated plasmas are calculated self-consistently using the predicted densities and temperatures. These simulations are compared to the best DT performance achieved to date in the supershot mode [16].

Modeling has shown that an acceptable neutral beam fueling system for a reactor is possible if the particle confinement approaches the neoclassical level [17]. The ERS mode thus may enable the use of core fueling systems to optimize the plasma density profile and thereby raise the fusion power output and improve the bootstrap alignment.

This paper examines the potential of the ERS mode for studies of burning plasmas in TFTR. The equilibrium ERS mode plasma conditions are noteworthy for strong heating by fusion-produced alphas, with nearly equal ion and electron temperatures at densities typical of reactors. The simulation with the highest performance has a $\beta_{\text {norm }} 10 \%$ higher than the highest value attained experimentally; the broader pressure profile in the simulation may enhance its MHD stability. We discuss the sensitivity of the results to several of the assumed plasma parameters. 


\section{SIMULATION METHOD}

Both steady state and time-dependent DT computer simulations of the ERS mode are reported here. Sensitivity studies are more easily done with the steady state code; the time-dependent simulations revealed that peak performance should occur well before the steady state conditions are established. All of the simulations are based on the thermal and particle diffusivities calculated by TRANSP [18-20] for a type I deuterium ERS discharge in TFTR [6]. The steady state simulations predict the density as well as the electron and ion temperatures. The density cannot be predicted with TRANSP so the time dependent simulations use an assumed density evolution which provides a transition from the measured density of an actual discharge to a steady state density profile.

The heating and particle fueling rates used to obtain steady state solutions of the one dimensional (1-d) diffusion equations are calculated by the SNAP transport analysis code [21]. For these calculations SNAP uses the temperatures and density predicted by a post-processor which solves the 1-d transport equations. Equilibrium is approached iteratively by using the temperatures and density predicted by the post-processor as the input to SNAP, which then calculates the appropriate source terms for the next iteration of the post-processor calculation. The density and temperature boundary conditions for the predictions are taken from the outermost zone of the SNAP analysis of the actual ERS shot.

The TRANSP [18-20] diffusivities are calculated from power and particle flux balance with no assumed pinch terms. (Analysis of tritium puffs in other ERS discharges shows that the tritium transport is suppressed relative to a supershot [22], and is consistent with the absence of a pinch in the plasma core [23].) The fluxes are based on time-dependent measurements of the electron density and temperature, the ion temperature, the visible bremsstrahlung emission (for $Z_{\text {eff }}$ ) together with calculations of the neutral beam deposition which determine the local heating and particle fueling. Particle fueling by the limiter gas influx is calculated from a neutral transport simulation which is normalized by the measured brightness of the $H_{\alpha}$ emission in front of the limiter. The analysis of the kinetic data agrees with the magnetically measured stored energy to $5 \%$. The calculated DD fusion rate is $20 \%$ higher than the measured DD neutron rate.

The diffusivities used for the simulations reported here are taken from TRANSP analysis runs which did not calculate ripple losses of the neutral beam injected fast ions. The steady state prediction code has no model for such losses, and the ripple model was turned off in the TRANSP projections reported here. A discussion of the sensitivity of the projections to beam ripple loss modeling is given below (see Discussion).

The inferred particle and ion thermal diffusivities can be quite low, but the uncertainties are relatively large so a minimum diffusivity of $0.02 \mathrm{~m}^{2} \mathrm{sec}^{-1}$ has been imposed. Some simulations have used neoclassical particle diffusivity (calculated for the predicted density and temperatures) as a lower bound for the particle diffusivity. We have used the full transport matrix calculation of the neoclassical electron flux from NCLASS to calculate the effective electron particle diffusivity [24]. It should be kept in mind, however, that the standard neoclassical formulations are not valid in the ERS mode discharges because the density and temperature scale lengths are close to the ion poloidal gyroradius and this contradicts ordering assumptions made in developing the theory. For electric fields of the magnitude expected near the magnetic axis in ERS discharges $(\sim 0.01 \mathrm{~V} / \mathrm{m})$ we find that Ware pinch effects may produce fluxes of the same magnitude as the total of all other terms in the inner $10 \%$ of the minor radius. In order to simplify the transport issues we have removed Ware pinch contributions to the fluxes by setting the toroidal electric field to zero.

In our simulations of the ERS mode we assume a radially constant $Z_{\text {eff }}$ in the range observed in the current experiments: 1.5-2.2. A visible bremsstrahlung array [25] and the brightness of carbon recombination light [26] are used separately to estimate the radial dependence of $Z_{\text {eff }}$. Both diagnostics indicate that $Z_{\text {eff }}$ is lower in the ERS mode than in similar shots with reversed shear that do not undergo a transition to enhanced confinement. Both diagnostics indicate that $Z_{\text {eff }}$ falls during the ERS mode throughout much of the plasma core. Diagnostic limitations complicate the interpretation of the measurements for $r<0.2 \mathrm{~m}$; in this region Zeff may be relatively constant as the electron density rises during the ERS mode.

In SNAP's calculation of the source terms, the beam deposition geometry includes the Shafranov 
shift of the plasma. This is important since the large stored energy and high $q(0)$ lead to a large shift which enhances neutral beam penetration to the high confinement region in the plasma core. The Shafranov shift calculated by SNAP for the actual ERS mode shot agrees with that in TRANSP to within $2 \mathrm{~cm}$ over almost all of the plasma. In turn, the TRANSP MHD equilibrium is consistent with the magnetic measurements.

The $q(r)$ measured by the MSE diagnostic $[27,28]$ prior to high power heating in the ERS mode discharge has a minimum value of 2 , at $r_{\min }=0.35 a$, and a central value of $\sim 3$. We expect that high performance experiments will use a higher plasma current, and lower $q_{\min }$, in order to improve the MHD stability at the highest possible stored energy. A preliminary series of MHD stability calculations [29] indicates that stability would be improved with with $q_{\min } \sim 1.3$, which we have adopted for these simulations (see Fig. 2)

At high $q(0)$, fusion-product alpha particles undergo large orbit excursions which broaden the alpha heating profile. This is modeled in SNAP by calculating orbits for a large sample of alphas distributed in birth minor radius, poloidal angle, and pitch angle. The deposited power is distributed throughout the range of minor radius traversed by each sample particle's initial orbit. This orbit broadening is quite pronounced when $q(0) \sim 2$ and reduces the alpha pressure gradient.

SNAP's very simple estimate of the effect of ripple trapping predicts alpha particle ripple losses of 8-12\% for the simulations in Tables I and II. A sophisticated guiding center code, ORBIT, indicates that the alpha ripple losses are $13 \%$ for the conditions of the deuterium ERS mode discharge which is the basis of these simulations [30]. The lower $q_{\min }$ and the shorter alpha thermalization time scale in the DT simulations reported here are expected to reduce the ripple losses below those for the deuterium discharge. The strong $q$ dependence of a simple analytic model for stochastic ripple diffusion [31] suggests that trapped alpha particles in RS/ERS plasmas would ripple transport to the vicinity of $r_{\min }$, causing a broadened alpha profile. However, ORBIT simulations [30] show that after one slowing down time, the alpha particle density profile is similar to that in simulations of comparable discharges with monotonic $q$ profiles.

Radiated power is measured to be negligible in the core of present ERS mode discharges, and impurity line radiation is expected to be small in the equilibrium conditions described in the next section. However, a simple calculation shows that in the projected conditions bremsstrahlung radiation losses would be as large as $20-50 \%$ of the local alpha 'birth' power. The ratio of radiated power to alpha heating power in the simulations is larger than this near the magnetic axis since orbit broadening reduces the central alpha power. Accordingly, the projected density and temperatures are used to calculate the expected bremsstrahlung radiation losses [32] which are used in predicting the electron temperature. This affects the predicted core ion temperature as well since temperature equilibration dominates the jon losses in the core.

For the simulations reported here the D:T neutral beam power ratio is chosen to be $1: 2$ because this has been found to maximize the fusion power in supershots (dominantly tritium neutral injection compensates for dominantly deuterium fueling from the limiter). Based on our experience in DT supershots the thermal density ratio is assumed to be

$$
n_{\mathrm{T}} /\left(n_{\mathrm{D}}+n_{\mathrm{T}}\right)=0.6 P_{\mathrm{T}} /\left(P_{\mathrm{D}}+P_{\mathrm{T}}\right),
$$

to account for the dominantly deuterium fueling by the limiter. The core density in the ERS mode may be relatively insensitive to the species mix of the particle influx from the limiter, so the optimal $\mathrm{D}: \mathrm{T}$ beam mix (and core mix) for the ERS mode may be closer to $1: 1$. The corresponding change in the thermal density mix from 60:40 to 50:50 D:T would raise the computed computed fusion power by $\sim 4 \%$.

Semi-predictive TRANSP simulations provide an estimate of the time dependence of how the temperatures approach equilibrium. The measured diffusivities are used to predict the temperatures which would be achieved by the combined beam and fusion product heating. The assumed density profile evolution joins the measured density in an ERS mode discharge to a steady state density profile. In the intial phase the TRANSP simulations use the measured density of an ERS mode shot. The density rise continues for an additional second, rising to the density predicted by a steady state simulation; the density is held constant for the remainder of the simulation. At each minor radius the density is interpolated linearly in time from the experimental profile to the predicted profile. 
Alpha particle orbit effects and the finite thermalization time are included in TRANSP's Monte Carlo simulation of fusion product thermalization. As in the corresponding steady state simulation, we assume $Z_{\text {eff }}=1.5$ and $P_{\mathrm{b}}=33 \mathrm{MW}$ during the period when the temperatures are predicted.

\section{RESULTS}

The equilibrium ERS mode DT simulations reported here are strikingly different from present TFTR discharges. The very low particle diffusivity in the ERS region leads to a core density which is twice that in present ERS mode discharges [6,9] and supershots $[33,34,16,35]$. This high core density couples the electron and ion temperatures more tightly and, as a result, the projected steady state ion temperature is less than half the usual supershot level $[33,34,16,35]$.

We present the results for two reversed magnetic shear configurations. The first has a minimum in $q(r)$ at $r_{\min }=0.35 a$, which corresponds to the location of $r_{\min }$ in early ERS mode discharges in TFTR. The second has $r_{\min }=0.45 a$, which has been achieved in subsequent TFTR experiments. For the simulations with $r_{\min }=0.45 a$ the core diffusivities have been shifted outward by $10 \%$ of the minor radius since the region of good confinement expands with the region of reversed shear.

The steady state results are summarized in Tables I and II (with $r_{\min }=0.35 a$ and $r_{\min }=0.45 a$, respectively). The simulations can be compared with actual discharge parameters given in the first column: Table I summarizes a deuterium-only ERS mode discharge [6], and Table II contains the highest fusion power supershot to date [16].

The first column in Table I lists the parameters of the deuterium ERS mode discharge on which we have based the projections. The next column is a DT projection to steady state with the same beam power and $Z_{\text {eff }}$ as the deuterium discharge. While the equilibrium $W_{\text {tot }}$ is close to that of the deuterium shot, the density and temperatures are strikingly different. As shown in the second DT simulation column of Table I, performance is dramatically increased by lowering $Z_{\text {eff }}$ to 1.5 and improving beam penetration (with roughly equal effects on performance). The beam penetration was improved by 1) raising the beam voltages to $105 \mathrm{keV}$ for deuterium and $120 \mathrm{keV}$ for tritium, and 2 ) using the lower $R_{\text {tang }}$ beamlines for tritium. The predicted core density and temperatures rise; the rise in ion temperature is quite effective in raising the fusion power because the thermal-thermal reaction rate increases strongly with temperature. All subsequent simulations assume these beam voltages and tritium source selections.

The next simulation in Table I tests the sensitivity of the projection to the core diffusivity. When the minimum particle diffusivity is set by standard neoclassical predictions (at the simulated conditions) the central density drops, which decouples the temperatures somewhat and allows the ion temperature to rise; the net change in both total stored energy and fusion power is negligible, however. For the last case shown in Table I we raised the beam power to $33 \mathrm{MW}$ and raised the gas influx from the limiter proportionately; this simulation is otherwise similar to the second column of DT simulations. The higher gas influx raises the plasma density in the outer region of the discharge, which reduces the fraction of the beam power which reaches the high confinement core. The reduced beam penetration leads to a very modest increase in core density and nearly the same temperatures that were produced by $25 \mathrm{MW}$ of heating; nevertheless the stored energy and fusion power are somewhat higher.

The lower section in Tables I and II summarizes the core $Q$ and confinement time scales. The parameters are averaged over the indicated region, which was chosen to enclose half the total alpha heating power. The alpha heating power (this includes the orbit broadening effect) is used in calculating $Q_{\alpha}$ heat.

In Table II we present the parameters of the best DT supershot and the projections with $r_{\min }=0.45 a$. The first DT simulations in Table II uses the actual neutral beam power of the ERS DD shot from which the diffusivities are taken. The second has higher beam power (and limiter gas influx) but is otherwise based on the same assumptions. Once again the higher power increases the core density slightly but does not change the temperatures; as described above the higher density in the outer part of the plasma is responsible for lowering the beam penetration.

The third simulation column uses thermal diffusivities from an earlier time in the ERS phase of the deuterium basis shot. The inferred ion thermal diffusivity is not strongly reduced in the 
core at this time, but the inferred electron thermal diffusivity is substantially lower than at later times. The predicted stored energy is modestly lower; the fusion power is $25 \%$ lower because the thermal-thermal component falls rapidly with $T_{i}$ at these temperatures.

In the final simulation the gas influx from the limiter was reduced in order to lower the density in the outer region of the plasma by $15 \%$ to determine the effect of improved beam penetration. This minor change has a strong effect on performance: the stored energy rises $22 \%$ and the fusion power increases $50 \%$. Perhaps this density reduction could be accomplished by using more extensive lithium conditioning, but well conditioned experiments to date show that the density is very closely determined by the beam power alone.

The plasma profiles in (Figs. 3-4) are taken from the last simulation in Table I and the second simulation in Table II. All differences in the input arise from an assumed increase in the size of the ERS region. The density profiles shown in Fig. 3a have a large density gradient just inside $r_{\min }$; this is characteristic of actual type I discharges and all the ERS mode simulations.

Comparing matched simulations in Tables I and II (second and fourth columns of DT simulations in Table I compared to first and second, respectively, in Table II) we see that enlarging the high confinement core does not increase the central density, and the central temperatures drop slightly. This occurs because the larger high confinement core leads to a larger region of high density, which leads to broader beam deposition (Fig. 3b). The central particle fueling rate is lowered and the density profile is much flatter near the magnetic axis. The broader beam heating profile is less effective in raising the central temperatures, particularly the ion temperature.

In all steady state ERS mode simulations the density is sufficiently high that electron-ion temperature equilibration dominates the ion power balance in the core. As a result, the ion temperature is much lower than in supershots and approaches the electron temperature (Fig. 4). The peak ion temperature is located off-axis with $r_{\min }=0.45 a$ because the beam heating is peaked off-axis; temperature equilibration pulls the central ion temperature down.

Semi-predictive TRANSP simulations provide a time dependent view of the approach to thermal equilibrium. Predictions with and without alpha heating illustrate the effect of self-heating. The density rise, occurring between 2.5 and 4.0 seconds (Fig. 5), gradually raises the temperature equilibration power. This is responsible for the declining ion temperature after 2.9 seconds, and it contributes to the increasing electron temperature before 4 seconds (Fig. 6). The total stored energy peaks during the density rise (Fig. 7), and subsequently falls toward its steady state level (see DT simulation column 2 in Table II). The 'overshoot' in stored energy is caused by the larger effective beam heating power at this time (with a rising density the energy transferred to thermal particles exceeds the steady state level of beam heating), and by the better beam penetration which arises from the lower density. The 'overshoot' in fusion power is even larger because at early times the ion thermal inertia and lower temperature coupling contribute to a much larger separation of $T_{\mathrm{i}}$ and $T_{\mathrm{e}}$ than is possible later in thermal equilibrium. Consequently, the peak fusion power is $25 \mathrm{MW}$ and the core $Q_{\mathrm{DT}}$ peaks at 2 (double the steady state levels).

In summary, we find that the equilibrium ERS mode DT plasma conditions are noteworthy for their nearly equal ion and electron temperatures at densities typical of reactors. The peak fusion performance is expected to be substantially higher than the equilibrium levels, thereby improving the prospects for alpha heating experiments in conditions similar to those proposed for advanced tokamak reactors.

\section{DISCUSSION}

The low core particle diffusivity of the ERS mode leads to high projected densities which closely couple the electron and ion temperatures. As a result, the steady state central ion temperatures are lower than the optimal values for fusion (which are $\sim 15 \mathrm{keV}$ ). In time dependent simulations the fusion power peaks during the density rise when the ion temperature is near the optimal level. While the peak fusion power can be its steady state value, the peak total stored energy is only slightly higher than its steady state value. The best conditions for alpha experiments will generally occur slightly after the time of peak fusion power. It may be possible to prolong the phase of high fusion 
power - or even enhance it - by using heating systems which introduce fewer particles (e.g., ICRH or high energy neutral beams) to replace some of the standard TFTR beams.

As in other enhanced confinement regimes, the plasma performance is ultimately limited by MHD stability [36]. We use PEST [37] to calculate the stability of equilibria using a projected pressure profile shape (typical of the cases in Table II) together with $q$ profiles which are qualitatively similar to those found in ERS discharges. The equilibria can be stable for ideal MHD instabilities with $n=1,2,3,4$ and $\infty$ up to $\beta_{\text {norm }}=2.5$. The fusion power is more closely related to

$$
\beta^{*}=\sqrt{\left\langle p^{2}\right\rangle}\left(2 \mu_{\mathrm{o}} / B_{\mathrm{tor}}^{2}\right)
$$

so a more meaningful way of expressing the limit is $\beta_{\text {norm }}^{*}=4.5$. The strong pressure peaking, $p(0) /\langle p\rangle=5$, raises $\beta^{*} / \beta$ to 1.8 and is responsible for the high critical $\beta_{\text {norm. }}^{*}$. At TFTR's maximum toroidal field, and with $I_{\mathrm{p}}=2.5 \mathrm{MA}$, the $\beta$ limit corresponds to $W_{\text {tot }}=11 \mathrm{MJ}$.

All the projections are below this limit, and most are below the maximum experimentally attained $\beta_{\text {norm }}$ of 1.9. However, stability is not assured - as demonstrated by disruptions of ERS discharges with $\beta_{\text {norm }} \leq 1.5$ - because the MHD stability is sensitive to the details of the pressure and $q$ profiles. As previously noted in studies of MHD stability with reversed shear $[1,38]$, the location of $q_{\min }$ in relation to the region of high pressure gradient plays a critical role. When $r_{\min }$ varies from 0.4 to $0.6 a$ (with a fixed pressure profile) the stability limit varies from $\beta_{\text {norm }}^{*}=1.6$ to 2.5 for the case described above. For this reason TFTR will use mode-conversion current drive to modify $q(r)$ and improve stability. However, if the region of very low diffusivity, which causes the high pressure gradient, is intimately related to the shear reversal, then the relative locations of $r_{\min }$ and the peak pressure gradient may not be changed easily. A detailed understanding of the conditions needed for transition to the ERS mode could provide guidance on whether (and how) $r_{\min }$ and the peak pressure gradient may be partially decoupled.

The system which measures the density in TFTR does not sample the region very close to the magnetic axis in ERS mode discharges, so the density in the innermost $\sim 15 \mathrm{~cm}$ is not known. If we assume that the density profile is flattened inside the position of the innermost measurement, then the inferred diffusivities differ from those assumed here. The central particle diffusivity becomes much higher, and the change in electron-ion coupling leads to a higher $\chi_{\mathrm{i}}$ and a lower $\chi_{\mathrm{e}}$. Simulations based on these alternate diffusivities have lower central density, and higher central temperatures than the reference case (DT simulation column 2 in Table II); the resulting fusion power is $4 \%$ lower.

The inferred particle diffusivity in these TRANSP simulations indicates that after 3.5 seconds the postulated density rise for $r<a / 3$ is too rapid to be consistent with the assumed diffusivity and the self consistently calculated beam fueling rate. A time dependent density prediction would evidently have a broader density profile in the core region (perhaps slightly hollow), and the central density would rise somewhat more slowly than we assumed in the simulation. The existing simulation therefore underestimates the core temperatures, and probably underestimates the fusion power, during the time of peak performance. We expect that the differences would be relatively modest, and would not qualitatively affect the character of the simulation.

The core thermal and particle confinement times in Tables I and II indicate that a two second heating pulse would be sufficiently long for the discharges to approach thermal equilibrium, but the core particle confinement time is two seconds in the cases with larger $r_{\min }$. On the other hand the time dependent simulations indicate that the highest performance will occur well before full equilibrium is established, so two seconds of high power heating should be sufficient to reach peak performance.

The transport analysis DT projections discussed above have assumed there are no ripple losses of beam ions or alphas. Transport analysis runs which include TRANSP's calculation of beam ripple losses infer that $\chi_{\mathrm{i}}$ is lower and $\chi_{\mathrm{e}}$ is higher than shown in Fig. 1. If these diffusivities are used in a DT TRANSP simulation which calculates bearn ripple losses using the same $q$ profile used in the analysis run, then we find predicted temperatures which are close to those in Fig. 6. There is little change because the ripple losses in the analysis and prediction are similar. However, if the ripple losses in future DT experiments can be reduced by lowering $q(0)$, then performance could be significantly improved. Unfortunately, there is considerable uncertainty in the actual $q(0)$ in the experiments, so the calculated ripple losses are uncertain. We have not assumed that ripple losses can be lowered in any of the DT simulations reported here. 
Applying the ERS mode to large power producing reactors raises new issues for further study: how can the fuel be supplied to the high confinement region, and how can the ash produced there be removed? Enlarging the radial extent of the high confinement region may be the key to developing answers to the first of these questions.

An acceptable fueling system must provide fuel to the region of high confinement while consuming a modest level of the power output. Previous work [17] shows that this could be done with a neutral beam system if the particle confinement is very good - as it is in the ERS mode - and if little of the beam fueling is deposited in low confinement regime. Enlarging the good confinement region also improves the prospects for pellet fueling, which was found to be a promising core fueling method.

Good confinement of the helium ash is not desirable, however. Helium ash buildup will not limit reactivity in TFTR experiments because the discharge duration will be too short. Ash transport and removal $[39,40]$ studies could, nevertheless, be carried out to assess the viability of the ERS mode in a long pulse power producing tokamak. Moving the ash outside the high confinement core would be sufficient since ash transport in the surrounding supershot regime is adequate to prevent serious buildup [26].

Although the central fusion power density for the ERS projections is very high, the peak alpha pressure and its gradient do not exceed those in the best DT supershot to date with $P_{\mathrm{f}}=11 \mathrm{MW}$. This paradox is caused by the the higher density in ERS mode, which reduces the thermalization time, and by the larger alpha orbit-broadening, which follows from the higher $q(0)$. The orbit broadening creates a larger region of high alpha pressure and moves the location of the peak gradient to larger minor radius. Nevertheless, the ERS mode provides an alpha physics test bed with a magnetic configuration which is more relevant to advanced tokamaks.

Recent experimental progress toward realization of the simulations described above has been encouraging: the ERS regime has been extended to higher plasma current (2.2 MA), the reversed shear region has been enlarged to $0.5 a$, and the region of excellent confinement has expanded to $0.5 a$. On the other hand, while discharges with $I_{\mathrm{p}}=1.6 \mathrm{MA}$ have reached $\beta_{\text {norm }}=1.9$, we have not yet surpassed $\beta_{\text {norm }}=1.5$ with $I_{\mathrm{p}}=2.2 \mathrm{MA}$, and it is clear that MHD stability must be improved in order to obtain long pulse high performance DT discharges in the ERS mode. We have also observed that it is more difficult to obtain the ERS mode in the 2.2 MA discharges. Lithium pellet injection at the beginning of the high power phase can be used to obtain ERS transitions in these high current discharges, but this results in abnormally low fusion power which appears to be caused by dilution due to lithium trapped in the high confinement region in the plasma core. Some other means of inducing the ERS transition must be used when attempting to produce the high fusion power ERS mode DT plasmas described here.

The fusion power of DT discharges in the ERS mode has been relatively low. This is partly because the duration of the high power heating phase is short (to avoid disruptions), and partly because the D:T mix of the heating beams is not optimal in these discharges. In addition, it now appears that the ERS threshold power is higher in plasmas with more optimal D:T ratios.

\section{SUMMARY}

The exceptionally low particle diffusivity observed in the ERS mode TFTR discharges $[6,9]$ is the key ingredient in our steady state ERS mode simulations. The presently observed density increases are expected to continue until the core density reaches $\sim 2.5 \times 10^{20} \mathrm{~m}^{-3}$. At this density the better coupled electron and ion temperatures more closely resemble the temperatures of an ignited plasma. In the plasma core the fusion self-heating is substantial, with core $Q_{\mathrm{DT}} \sim 1-2$. Realization of these conditions would provide an early opportunity to conduct alpha physics experiments in an advanced tokamak configuration.

\section{ACKNOWLEDGEMENTS}

It is a pleasure to thank R. J. Hawryluk and K. M. McGuire for their encouragement of this work as well as S. H. Batha, M. G. Bell, R. E. Bell, R. V. Budny, C. E. Bush, P. C. Efthimion, 
F. M. Levinton, M. W. Phillips A. T. Ramsey, M. H. Redi, and E. J. Synakowski for enlightening discussions. This work was supported by U.S. DoE Contract No. DE-AC02-76CH03073.

[1] T. Ozeki, M. Azumi; T. Tsunematsu, K. Tani, M. Yagi, , and S. Tokuda, Profile control for a stable high bpol tokamak with a large bootstrap fraction, in Plasma Physics and Controlled Nuclear Fusion Research (Proc. 14th Int. Conf., Wurzburg, 1992), volume 2, pp. 187-194, Vienna, 1993, International Atomic Energy Agency.

[2] C. Kessel, J. Manickam, G. Rewoldt, and W. M. Tang, Phys. Rev. Lett. 72, 1212 (1994).

[3] A. D. Turnbull, T. S. Taylor, Y. R. Lin-liu, and H. S. John, Phys. Rev. Lett. 74, 718 (1995).

[4] M. Hugon, B. P. van Milligen, P. Smeulders, L. C. Appel, D. V. Bartlett, D. Boucher, A. W. Edwards, L.-G. Eriksson, C. W. Gowers, T. C. Hender, G. Huysmans, J. J. Jacquinot, P. Kupschus, L. Porte, P. H. Rebut, D. F. H. Start, F. Tibone, B. J. D. Tubbing, M. L. Watkins, and W. Zwingmann, Nucl. Fusion 32, 33 (1992).

[5] E. A. Lazarus, L. L. Lao, T. H. Osborne, T. S. Taylor, A. D. Turnbull, M. S. Chu, A. G. Kellman, E. J. Strait, J. R. Ferron, R. L. Groebner, W. W. Heidbrink, T. Carlstrom, F. J. Helton, C. L. Hsieh, S. Lippmann, D. Schissel, R. Snider, and D. Wroblewski, Phys. Fluids B 4, 3644 (1992).

[6] F. M. Levinton, M. C. Zarnstorf, S. H. Batha, M. Bell, R. E. Bell, R. V. Budny, C. Bush, Z. Chang, E. Fredrickson, A. Janos, H. Park, A. Ramsey, G. L. Schmidt, E. Synakowski, and G. Taylor, Phys. Rev. Lett. 75, 4417 (1995).

[7] E. J. Strait, L. L. Lao, M. E. Mauel, B. W. Rice, T. S. Taylor, K. H. Burrell, M. S. Chu, E. A. Lazarus, T. H. Osborne, S. J. Thompson, and A. D. Turnbull, Phys. Rev. Lett. 75, 4421 (1995).

[8] H. Kimura and the JT-60 Team, Phys. Plasmas 3, 1943 (1996).

[9] F. M. Levinton, S. H. Batha, M. Beer, M. G. Bell, , R. E. Bell, R. V. Budny, C. Bush, P. Efthimion, E. Mazzucato, R. Nazikian, H. Park, A. Ramsey, G. L. Schmidt, S. Scott, E. J. Synakowski, G. Taylor, S. von Goeler, and M. C. Zarnstorf, Transport physics in reversed shear plasmas, in Plasma Physics and Controlled Nuclear Fusion Research (Proc. Sixteenth Intl. Conf., Montreal, 1996), Vienna, 1996, International Atomic Energy Agency, to be published, paper IAEA-CN-64/A1-3.

[10] B. W. Rice, K. H. Burrell, L. L. Lao, G. Navratil, B. W. Stallard, E. J. Strait, T. S. Taylor, M. E. A. adn T A Casper, M. S. Chu, C. B. Forest, P. Gohil, R. J. Groebner, W. W. Heidbrink, A. W. Hyatt, H. Izeki, R. J. La Haye, E. A. Lazarus, L. Y. R, M. E. Manel, W. H. Meyer, C. L. Rettig, D. P. Schissel, H. E. St. John, P. L. Taylor, A. D. Turnbull, and the DIII-D Team, Phys. Plasmas 3, 1983 (1996).

[11] D. P. Schissesl, C. M. Greenfield, J. C. DeBoo, L. L. Lao, E. A. Lazarus, G. A. Navratil, B. W. Rice, G. M. Staebler, B. W. Stallard, E. J. Strait, H. E. St. John, M. E. Austin, K. H. Burrell, T. A. Casper, D. R. Baker, V. S. Chan, E. J. Doyle, J. R. Ferron, C. B. Forest, P. Gohil, R. J. roebner, W. W. Heidbrink, R.-M. Hong, A. W. Howald, C.-L. Hseih, A. W. Hyatt, G. L. Jackson, J. Kim, C. J. Lasnier, A. W. Leonard, J. Lohr, R. J. La Haye, R. Maingi, R. L. Miller, M. Murakami, T. H. Osborne, C. C. Petty, C. L. Retig, T. L. Rhodes, S. S. adn T C Scoville, R. T. Snider, R. D. Stambough, R. E. Stockdale, P. L. Taylor, T. S. Taylor, D. M. Thomas, M. R. Wade, R. E. Waltz, R. D. Wood, and D. G. Whyte, Local analysis of confinement and transport in neutral beam heated DIII-D discharges with negative magnetic shear, in Plasma Physics and Controlled Nuclear Fusion Research (Proc. Sixteenth Intl. Conf., Montreal, 1996), Vienna, 1996, International Atomic Energy Agency, to be published, paper IAEA-CN-64/A5-3.

[12] T. Fujita, S. Ide, H. Kimura, Y. Koide, T. Ojkawa, S. Takeji, H. Shirai, T. Ozeki, Y. Kamada, S. Ishida, and the JT-60 Team, Enhanced core confinement in JT-60U reversed shear discharges, in Plasma Physics and Controlled Nuclear Fusion Research (Proc. Sixteenth Intl. Conf., Montreal, 1996), Vienna, 1996, International Atomic Energy Agency, to be published, paper IAEA-CN-64/A1-4.

[13] C. Gormezano and the JET Team, Optimization of JET plasmas with current profile control, in Plasma Physics and Controlled Nuclear Fusion Research (Proc. Sixteenth Intl. Conf., Montreal, 1996), Vienna, 1996, International Atomic Energy Agency, to be published, paper IAEA-CN-64/A5-5.

[14] K. C. Shaing, C. T. Hsu, and N. Dominguez, Phys. Plasmas 1, 1168 (1994).

[15] Z. Lin, W. M. Tang, and W. W. Lee, Phys. Rev. Lett. 78, 456 (1997).

[16] K. M. McGuire, K. M. McGuire, H. Adler, P. Alling, C. Ancher, H. Anderson, J. L. Anderson, J. W. 
Anderson, V. Arunasalam, G. Ascione, D. Ashcroft, C. W. Barnes, G. Barnes, S. Batha, G. Bateman, M. Beer, M. G. Bell, R. Bell, M. Bitter, W. Blanchard, N. L. Bretz, C. Brunkhorst, R. Budny, C. E. Bush, R. Camp, M. Caorlin, H. Carnevale, S. Caufman, Z. Chang, C. Z. Cheng, J. Chrzanowski, J. Collins, G. Coward, M. Cropper, D. S. Darrow, R. Daugert, J. D. Looper, W. Dorland, L. Dudek, H. Duong, R. Durst, P. C. Efthimion, D. Ernst, H. Evenson, N. J. Fisch, R. Fisher, R. J. Fonck, E. Fredd, E. Fredrickson, N. Fromm, G. Y. Fu, T. Fujita, H. P. Furth, V. Garzotto, C. Gentile, J. Gilbert, J. Gioia, N. Gorelenkov, B. Grek, L. R. Grisham, G. Hammett, G. R. Hanson, R. J. Hawryluk, W. Heidbrink, H. W. Herrmann, K. W. Hill, J. Hosea, H. Hsuan, M. Hughes, R. Hulse, A. Janos, D. L. Jassby, F. C. Jobes, D. W. Johnson, L. C. Johnson, M. Kalish, J. Kamperschroer, J. Kesner, H. Kugel, G. Labik, N. T. Lam, P. H. LaMarche, E. Lawson, B. LeBlanc, J. Levine, F. M. Levinton, D. Loesser, D. Long, M. J. Loughlin, J. Machuzak, R. Majeski, D. K. Mansfield, E. S. Marmar, R. Marsala, A. Martin, E. Mazzucato, M. Mauel, M. P. McCarthy, J. McChesney, B. McCormack, D. C. McCune, G. McKee, D. M. Meade, S. S. Medley, D. R. Mikkelsen, S. V. Mirnov, D. Mueller, M. Murakami, J. A. Murphy, A. Nagy, G. A. Navratil, R. Nazikian, R. Newman, M. Norris, T. O'Connor, M. Oldaker, J. Ongena, M. Osakabe, D. K. Owens, H. Park, W. Park, P. Parks, S. F. Paul, G. Pearson, E. Perry, R. Persing, M. Petrov, C. Kieras-Phillips, M. Phillips, S. Pitcher, R. Pysher, A. L. Qualls, S. Raftopoulos, S. Ramakrishnan, A. Ramsey, D. A. Rasmussen, M. H. Redi, G. Renda, G. Rewoldt, D. Roberts, J. Rogers, R. Rossmassler, A. L. Roquemore, E. Ruskov, S. A. Sabbagh, M. Sasao, G. Schilling, J. Schivell, G. L. Schmidt, R. Scillia, S. D. Scott, 1, Semenov, T. Senko, S. Sesnic, R. Sissingh, C. H. Skinner, J. Snipes, J. Stencel, J. Stevens, T. Stevenson, B. C. Stratton, J. D. Strachan, W. Stodiek, J. Swanson, E. Synakowski, H. Takahashi, W. Tang, G. Taylor, J. Terry, M. E. Thompson, W. Tighe, J. R. Timberlake, K. Tobita, H. H. Towner, M. Tuszewski, A. von Halle, C. Vannoy, M. Viola, S. von Goeler, D. Voorhees, R. T. Walters, R. Wester, R. White, R. Wieland, J. B. Wilgen, M. Williams, J. R. Wilson, J. Winston, K. Wright, K. L. Wong, P. Woskov, G. A. Wurden, M. Yamada, S. Yoshikawa, K. M. Young, M. C. Zarnstorff, V. Zayereev, and S. J. Zweben, Phys. Plasmas 2, 2176 (1995).

[17] D. R. Mikkelsen, K. M. McGuire, G. L. Schmidt, S. J. Zweben, S. E. Attenberger, W. A. Houlber, and S. L. Milora, Nucl. Fusion 35, 521 (1995).

[18] R. J. Hawryluk, in Physics of Plasmas Close to Thermonuclear Conditions (Proc. Course Varenna, 1979), volume 1, p. 19, Commision of the European Communities, Brussels, 1980.

[19] R. J. Goldston, in Basic Physical Processes of Toroidal Fusion Plasmas (Proc. Course and Workshop Varenna, 1985), volume 1, p. 165, Monotypia Franchi, Perugia, 1986.

[20] M. C. Zarnstorff, K. McGuire, M. G. Bell, B. Grek, D. Johnson, D. McCune, H. Park, A. Ramsey, and G. Taylor, Phys. Fluids B 2, 1852 (1990).

[21] H. H. Towner, R. J. Goldston, G. W. Hammett, J. A. Murphy, C. Kieras-Phillips, S. D. Scott, M. C. Zarnstorff, and D. Smithe, Rev, Sci. Instrum. 63, 4753 (1992).

[22] P. C. Efthimion, L. C. Johnson, J. D. Strachan, E. J. Synakowski, M. Zarnstorff, H. Adler, C. Barnes, R. V. Budny, F. C. Jobes, J. Kampershroer, W. W. Lee, M. Louglin, D. McCune, D. Mueller, A. T. Ramsey, G. Rewoldt, A. L. Roquemore, D. P. Stotler, W. M. Tang, and G. Taylor, Phys. Rev. Lett. 75,85 (1995).

[23] P. C. Efthimion, Princeton Plasma Physics Laboratory, 1995, private communication.

[24] W. Houlberg, Oak Ridge National Laboratory, 1995, private communication.

[25] A. T. Ramsey and S. L. Turner, Rev. Sci. Instrum. 58, 1211 (1987).

[26] E. J. Synakowski, P. C. Efthimion, G. Rewoldt, B. C. Stratton, W. M. Tang, B. Grek, K. W. Hill, R. A. Hulse, D. W. Johnson, M. W. Kissick, D. K. Mansfield, D. McCune, D. R. Mikkelsen, H. K. Park, A. T. Ramsey, M. H. Redi, S. D. Scott, G. Taylor, J. Timberlake, and M. C. Zarnstorff, Phys. Fluids B 5, 2215 (1993).

[27] F. M. Levinton, R. J. Fonck, G. M. Gammel, R. Kaita, H. W. Kugel, E. T. Powell, and D. W. Roberts, Phys. Rev. Lett. 63, 2060 (1989).

[28] F. M. Levinton, Rev. Sci. Instrum. 63, 5157 (1992).

[29] M. Phillips, Northrup-Grumman, 1995, private communication.

[30] M. H. Redi, Princeton Plasma Physics Laboratory, 1996, private communication.

[31] R. J. Goldston, R. B. White, and A. H. Boozer, Phys. Rev. Lett. 47, 647 (1981).

[32] D. E. Post, R. V. Jensen, C. B. Tarter, W. H. Grasberger, and W. A. Lokke, Atomic Data and Nuclear Data Tables 20, 397 (1977).

[33] R. V. Budny, M. G. Bell, H. Biglari, M. Bitter, C. Bush, C. Z. Cheng, E. Frederickson, B. Grek, K. W. Hill, H. Hsuan, A. Janos, D. L. Jassby, D. Johnson, L. C. Johnson, B. LeBlanc, D. C. McCune, D. R. Mikkelsen, H. Park, A. T. Ramsey, S. A. Sabbagh, S. Scott, J. Schivell, J. D. Strachan, B. C. Stratton, 
E. Synakowski, G. Taylor, M. C. Zarnstorf, and S. J. Zweben, Nucl. Fusion 32, 429 (1992).

[34] R. J. Hawryluk, H. Adler, P. Alling, C. Ancher, H. Anderson, J. L. Anderson, D. Ashcroft, C. W. Barnes, G. Barnes, S. Batha, M. G. Bell, R. Bell, M. Bitter, W. Blanchard, N. Bretz, R. Budny, C. E. Bush, R. Camp, M. Caorlin, S. Cauffman, Z. Chang, C. Z. Cheng, J. Collins, G. Coward, D. S. Darrow, J. DeLooper, H. Duong, L. Dudek, R. Durst, P. C. Efthimion, D. Ernst, R. Fisher, R. J. Fonck, E. Fredrickson, N. Fromm, G. Y. Fu, H. P. Furth, C. Gentile, N. Gorelenkov, B. Grek, L. R. Grisham, G. Hammett, G. R. Hanson, W. Heidbrink, H. W. Herrmann, K. W. Hill, J. Hosea, H. Hsuan, A. Janos, D. L. Jassby, F. C. Jobes, D. W. Johnson, L. C. Johnson, J. Kamperschroer, H. Kugel, N. T. Lam, P. H. LaMarche, M. J. Laughlin, J. E. Lawson, B. LeBlanc, M. Leonard, F. M. Levinton, J. Machuzak, D. K. Mansfield, A. Martin, E. Mazzucato, R. Majeski, B. McCormack, D. C. McCune, K. M. McGuire, G. McKee, D. M. Meade, S. S. Medley, D. R. Mikkelsen, D. Mueller, M. Murakami, A. Nagy, R. Nazikian, R. Newman, T. Nishitani, M. Norris, T. O'Connor, M. Oldaker, M. Osakabe, D. K. Owens, H. Park, W. Park, S. F. Paul, G. Pearson, E. Perry, M. Petrov, C. Kieras-Phillips, S. Pitcher, S. Popovichev, A. Ramsey, D. A. Rasmussen, M. H. Redi, D. Roberts, J. Rogers, R. Rossmassler, A. L. Roquemore, S. A. Sabbagh, M. Sasao, G. Schilling, J. Schivell, G. L. Schmidt, S. D. Scott, R. Sissingh, C. Skinner, J. Snipes, J. Stevens, T. Stevenson, B. C. Stratton, J. D. Strachan, E. Synakowski, W. Tang, G. Taylor, J. Terry, M. E. Thompson, C. Vannoy, A. von Halle, S. von Goeler, D. Voorhees, R. T. W. R. Wieland, J. B. Wilgen, M. Williams, J. R. Wilson, K. L. Wong, G. A. Wurden, M. Yamada, K. M. Young, M. C. Zarnstorff, and S. J. Zweben, Phys. Rev. Lett. 72, 3530 (1994).

[35] S. D. Scott, D. R. Ernst, M. Murakami, H. Adler, M. G. Bell, R. Bell, R. V. Budny, C. E. Bush, Z. Chang, H. Duong, L. R. Grisham, E. D. Fredrickson, B. Grek, R. J. Hawryluk, K. W. Hill, J. Hosea, D. L. Jassby, D. W. Johnson, L. C. Johnson, M. J. Loughlin, D. K. Mansfield, K. M. McGuire, D. M. Meade, D. M. Mikkelsen, J. Murphy, H. K. Park, A. T. Ramsey, J. Schivell, C. H. Skinner, J. D. Strachan, E. J. Synakowski, G. Taylor, M. E. Thompson, R. Wieland, and M. C. Zarnstorff, Physica Scripta 51, 394 (1995).

[36] J. Manickam, E. Fredrickson, Z. Chang, M. Okabayashi, M. G. Bell, W. Park, G. L. Schmidt, M. C. Zarnstorff, the TFTR group, F. M. Levinton, S. H. Batha, T. C. Hender, C. G. Gimblett, R. J. Hastie, M. Phillips, and M. H. Hughes, MHD stability studies in reversed shear plasmas in TFTR, in Plasma Physics and Controlled Nuclear Fusion Research (Proc. Sixteenth Intl. Conf., Montreal, 1996), Vienna, 1996, International Atomic Energy Agency, to be published, paper IAEA-CN-64/A5-2.

[37] R. C. Grimm, R. L. Dewar, and J. Manickam, J. Comput. Phys. 49, 94 (1983).

[38] H. A. Holties, G. T. A. Huysmans, W. Kerner, J. P. Goedbloed, F. X. Soldner, and V. V. Parail, MHD stability of advanced tokamak scenarios, in Controlled Fusion and Plasma Physics (Proc. 21st European Physical Society Conf., Montpellier, 1994), volume 18B, Part I, pp. 234-237, Brussels, 1994, European Physical Society.

[39] H. E. Mynick and N. Pomphrey, Nucl. Fusion 34, 1277 (1994).

[40] N. J. Fisch, Phys. Plasmas 2, 2375 (1995). 


\section{Figure Captions}

1) The inferred particle and thermal diffusivities in a deuterium ERS mode discharge in TFTR.

2) The safety factor profiles used in the simulations with $r_{\min }=0.35 a$ and $r_{\min }=0.45 a$.

3) The a) electron density for equilibrium simulations with $r_{\min }=0.35 a$ and $r_{\min }=0.45 a$, and b) the electron source rate due to neutral beam ionization.

4) The a) electron, and b) ion temperatures (for cases in Fig. 3).

5) Assumed evolution of the electron density (temperatures in Fig. 6).

6) Predicted evolution of the central temperatures of a) electrons, and b) ions for simulations with and without alpha heating (density in Fig. 5).

7) Predicted time dependence of the total stored energy (see Fig. 6).

8) Predicted time dependence of the fusion power (see Fig. 6).

9) Predicted temperature profiles at the time of peak fusion power (see Fig. 6). 
Table I

ERS steady state DT simulations with $r_{\min }=\mathbf{0 . 3 5} a$ Deuterium-only ERS mode discharge in first column

\begin{tabular}{llllllll}
\hline \hline & & \multicolumn{3}{c}{ Deuterium } & \multicolumn{3}{c}{ DT simulations } \\
\hline Min. $D_{\mathrm{e}}$ & $\left(\mathrm{m}^{2} \mathrm{~s}^{-1}\right)$ & & 0.02 & 0.02 & $\mathrm{D}_{\mathrm{e}}^{\text {nea }}$ & 0.02 \\
$Z_{\text {eff }}$ & & 2.2 & 2.2 & 1.5 & 1.5 & 1.5 \\
$P_{\text {beam }}$ & $\mathrm{MW}$ & 25 & 25 & 25 & 25 & $\mathbf{3 3}$ \\
$E_{\text {beam }}$ & $\mathrm{keV}$ & 100 & 100 & $\mathbf{1 1 5}$ & 115 & 115 \\
$P_{\text {fusion }}$ & $\mathrm{MW}$ & & 5 & 11 & 11 & 15 \\
$W_{\text {tot }}$ & $\mathrm{MJ}$ & 3.6 & 4.1 & 5.4 & 5.2 & 6.4 \\
$n_{\mathrm{e}}(0)$ & $10^{20} \mathrm{~m}^{-3}$ & 1.2 & 2.0 & 2.2 & 1.8 & 2.5 \\
$T_{\mathrm{e}}(0)$ & $\mathrm{keV}$ & 8.0 & 6.6 & 8.1 & 8.0 & 8.2 \\
$T_{\mathrm{i}}(0)$ & $\mathrm{keV}$ & 19 & 8.9 & 11.8 & 12.5 & 11.6 \\
$R_{\mathrm{o}}$ & $\mathrm{m}$ & 2.59 & 2.59 & 2.59 & 2.59 & 2.59 \\
$a$ & $\mathrm{~m}$ & 0.94 & 0.94 & 0.94 & 0.94 & 0.94 \\
$B_{\text {toroidal }}$ & $\mathrm{T}$ & 4.6 & 5.8 & 5.8 & 5.8 & 5.8 \\
$I_{\mathrm{p}}$ & $\mathrm{MA}$ & 1.6 & 2.2 & 2.2 & 2.2 & 2.2 \\
$\left\langle\beta_{\text {toroidal }}^{\text {tot }}\right\rangle$ & $\%$ & 0.7 & 0.4 & 0.6 & 0.6 & 0.7 \\
$\beta_{\text {norm }}$ & & 1.9 & 1.1 & 1.4 & 1.4 & 1.7 \\
$S_{\text {neut }}^{\text {th }} / S_{\text {neut }}^{\text {tot }}$ & & 0.52 & 0.42 & 0.57 & 0.54 & 0.57
\end{tabular}

The following parameters are integrated over $r<0.30 a$

\begin{tabular}{lllllll}
$\tau_{\mathrm{E}}$ & sec & 0.22 & 0.24 & 0.28 & 0.27 & 0.28 \\
$Q_{\alpha \text { heat }}$ & & & 0.4 & 0.8 & 0.7 & 0.9 \\
$P_{\text {brem }} / P_{\alpha \text { heat }}$ & & & 0.6 & 0.2 & 0.2 & 0.2 \\
$\tau_{\mathrm{p}}$ & $\mathrm{sec}$ & 1.5 & 1.2 & 1.2 & 1.2 & 1.2 \\
\hline \hline
\end{tabular}


Table II

ERS steady state DT simulations with $r_{\min }=0.45 a$

DT supershot in first column

\begin{tabular}{|c|c|c|c|c|c|c|}
\hline \multirow{2}{*}{\multicolumn{2}{|c|}{$\begin{array}{ll}\text { Min. } D_{\mathrm{e}} & \left(\mathrm{m}^{2} \mathrm{~s}^{-1}\right)\end{array}$}} & \multirow{2}{*}{ Supershot } & \multicolumn{4}{|c|}{ DT simulations } \\
\hline & & & 0.02 & 0.02 & 20.02 & $0.02^{\dagger}$ \\
\hline$Z_{\text {eff }}$ & & 2.4 & 1.5 & 1.5 & 1.5 & 1.5 \\
\hline$P_{\text {beam }}$ & MW & 40 & 25 & 33 & 33 & 33 \\
\hline$E_{\text {beam }}$ & $\mathrm{keV}$ & 110 & 115 & 115 & 115 & 115 \\
\hline$P_{\text {fusion }}$ & MW & 11 & 9 & 12 & 9 & 18 \\
\hline$W_{\text {tot }}$ & MJ & 6.9 & 5.8 & 6.8 & 6.3 & 8.3 \\
\hline$n_{\mathrm{e}}(0)$ & $10^{20} \mathrm{~m}^{-3}$ & 1.1 & 2.2 & 2.4 & 2.4 & 2.7 \\
\hline$T_{e}(0)$ & $\mathrm{keV}$ & 13 & 6.3 & 6.3 & 6.0 & 7.3 \\
\hline$T_{\mathrm{i}}(0)$ & $\mathrm{keV}$ & 32 & 7.6 & 7.4 & 6.7 & 8.7 \\
\hline$R_{\circ}$ & $\mathrm{m}$ & 2.52 & 2.59 & 2.59 & 2.59 & 2.59 \\
\hline$a$ & $\mathrm{~m}$ & 0.87 & 0.94 & 0.94 & 40.94 & 0.94 \\
\hline$B_{\text {toroidal }}$ & $\mathrm{T}$ & 5.5 & 5.8 & 5.8 & 5.8 & 5.8 \\
\hline$I_{\mathrm{p}}$ & MA & 2.7 & 2.4 & 2.4 & 2.4 & 2.4 \\
\hline$\left\langle\beta_{\text {tot }}^{\text {tot }}\right\rangle$ & $\%$ & 1.1 & 0.6 & 0.7 & 0.7 & 0.9 \\
\hline$\beta_{\text {norm }}$ & & 1.9 & 1.4 & 1.6 & 1.5 & 2.0 \\
\hline$S_{\text {neut }}^{\text {th }} / S_{\text {neut }}^{\text {tot }}$ & & 0.25 & 0.51 & 0.51 & 0.39 & 0.62 \\
\hline \multicolumn{7}{|c|}{ The following parameters are integrated over $r<0.35 a$} \\
\hline$\tau_{\mathrm{E}}$ & sec & 0.34 & 0.35 & 0.35 & 50.32 & 0.39 \\
\hline$Q_{\alpha \text { heat }}$ & & 0.5 & 0.6 & 0.6 & 0.5 & 0.8 \\
\hline$P_{\text {brem }} / P_{\alpha}$ he & & & 0.4 & 0.4 & 0.5 & 0.3 \\
\hline$\tau_{\mathrm{p}}$ & $\sec$ & 0.44 & 2.0 & 2.0 & 2.0 & 1.9 \\
\hline
\end{tabular}

${ }^{*}$ Used diffusivities at $2.8 \mathrm{sec}$ in shot 84011 .

$\dagger$ Lowered the pedestal density $15 \%$. 


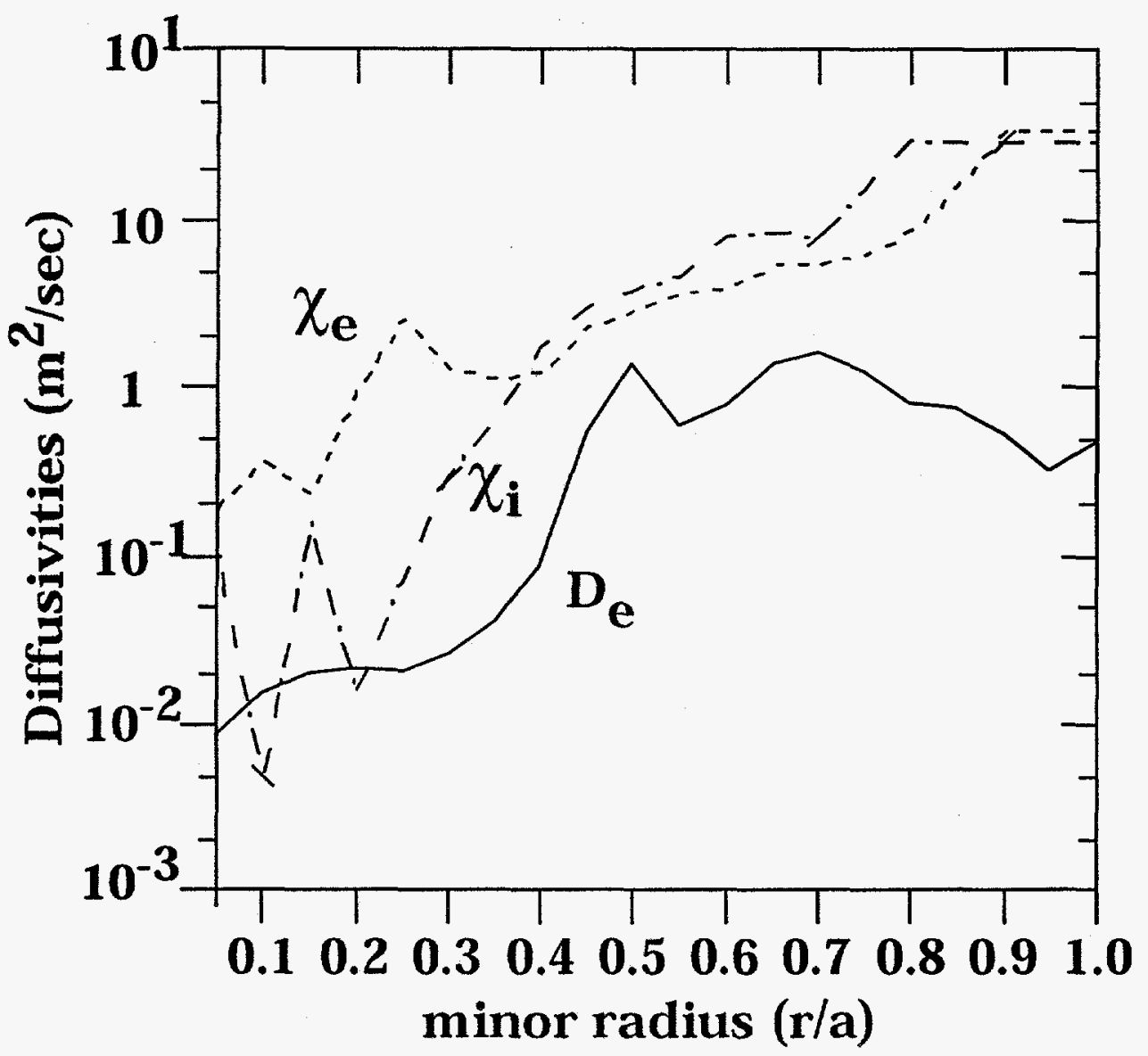

Fig. 1

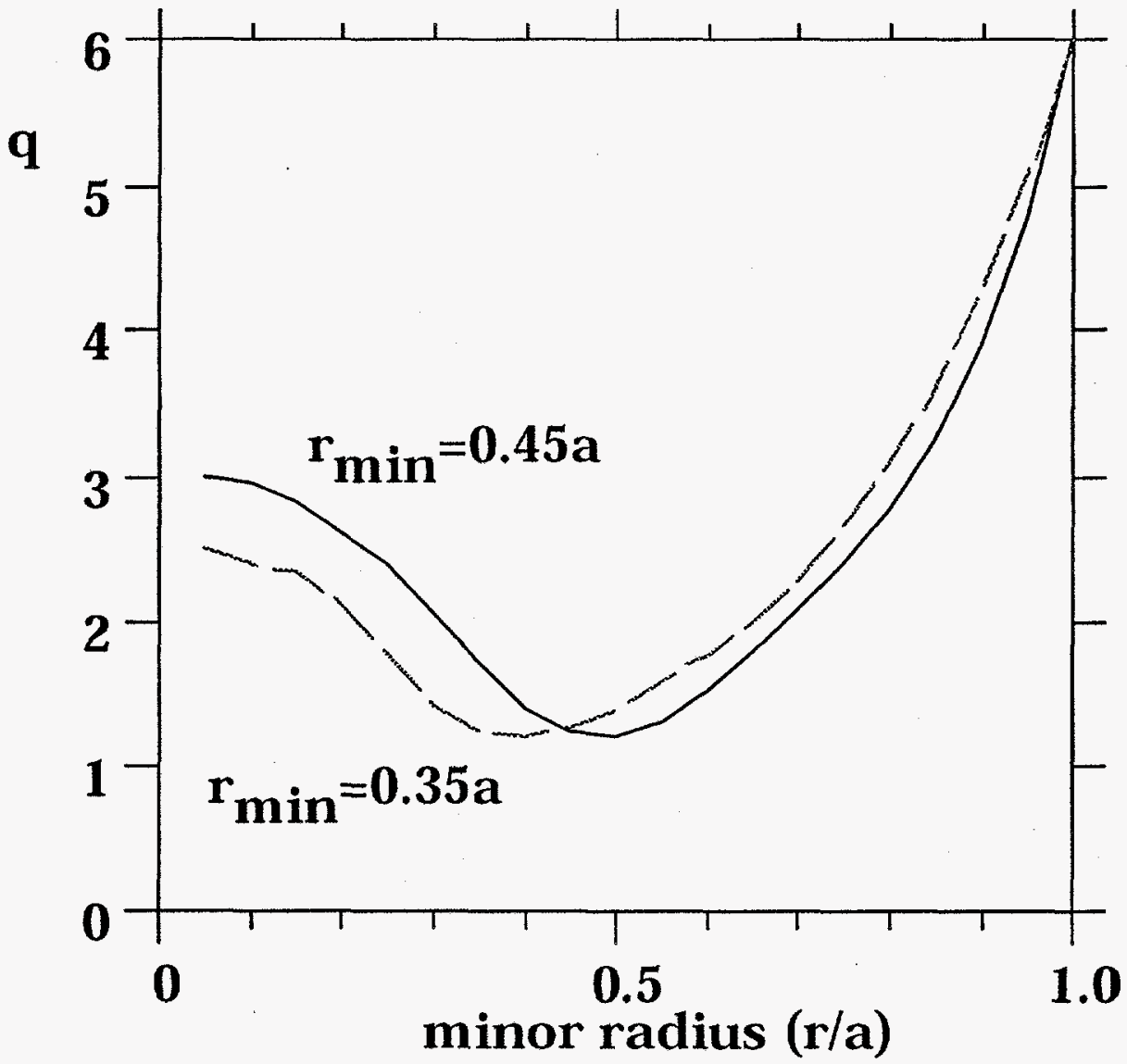

Fig. 2 

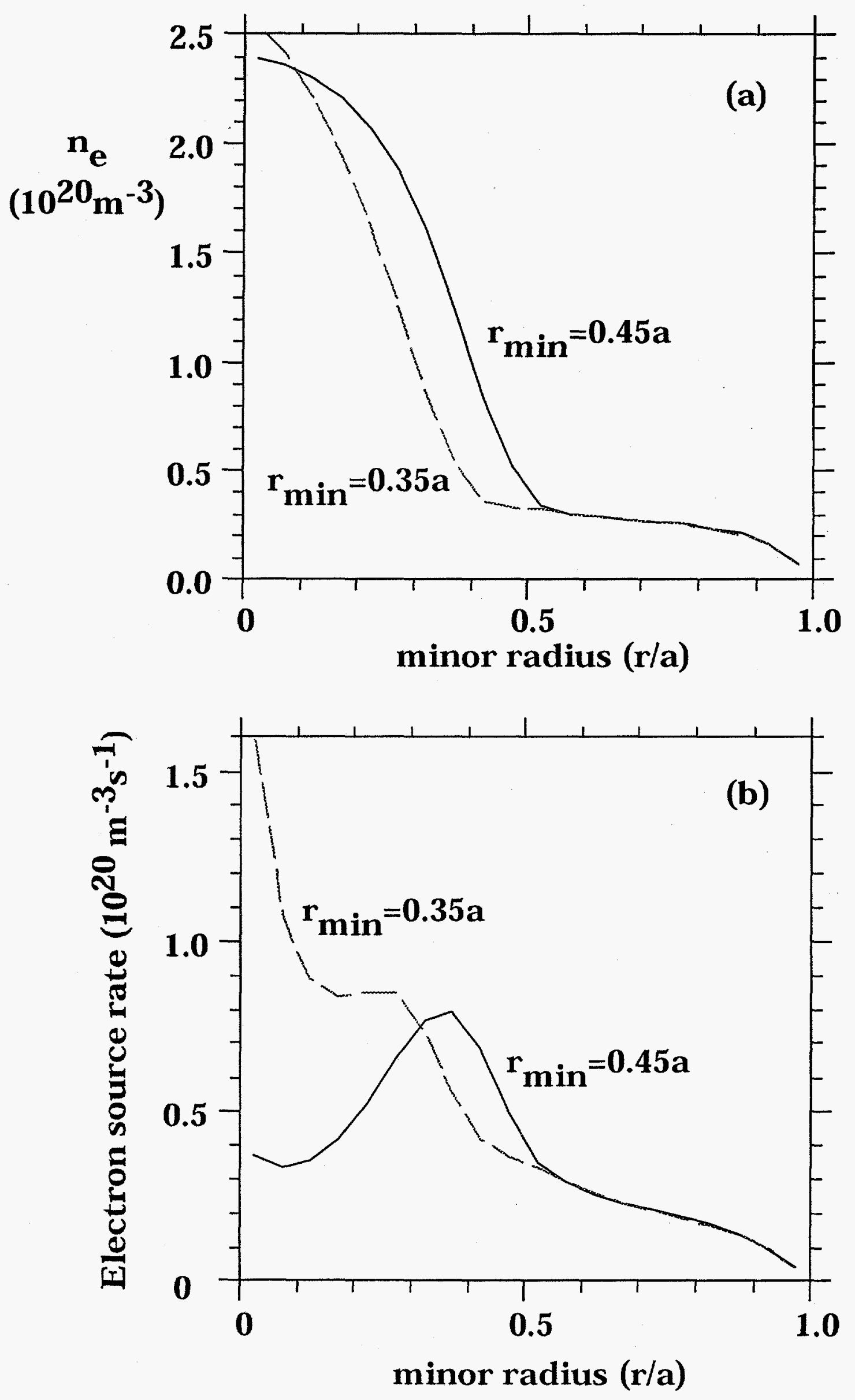

Fig. 3 

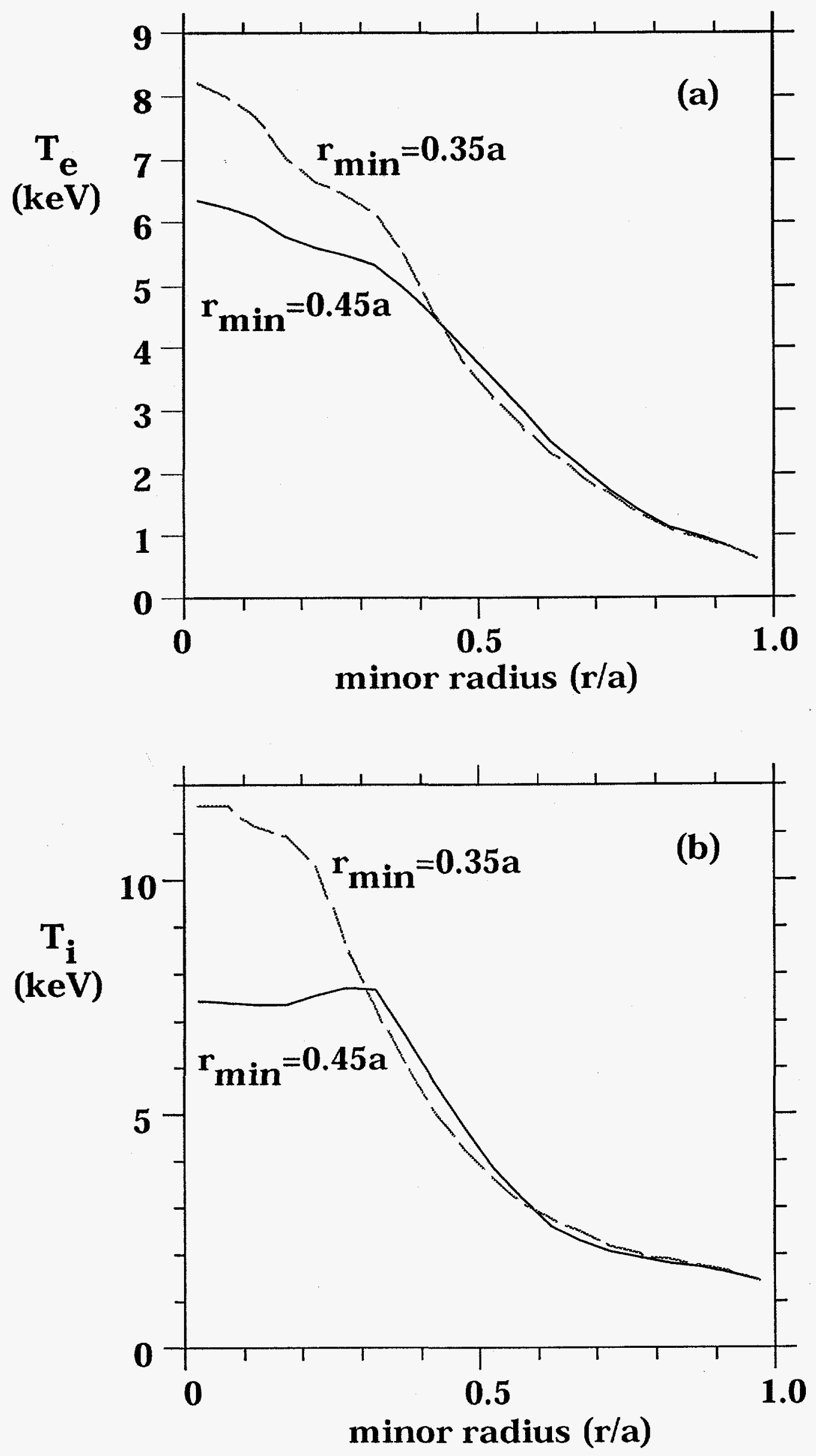

Fig. 4 


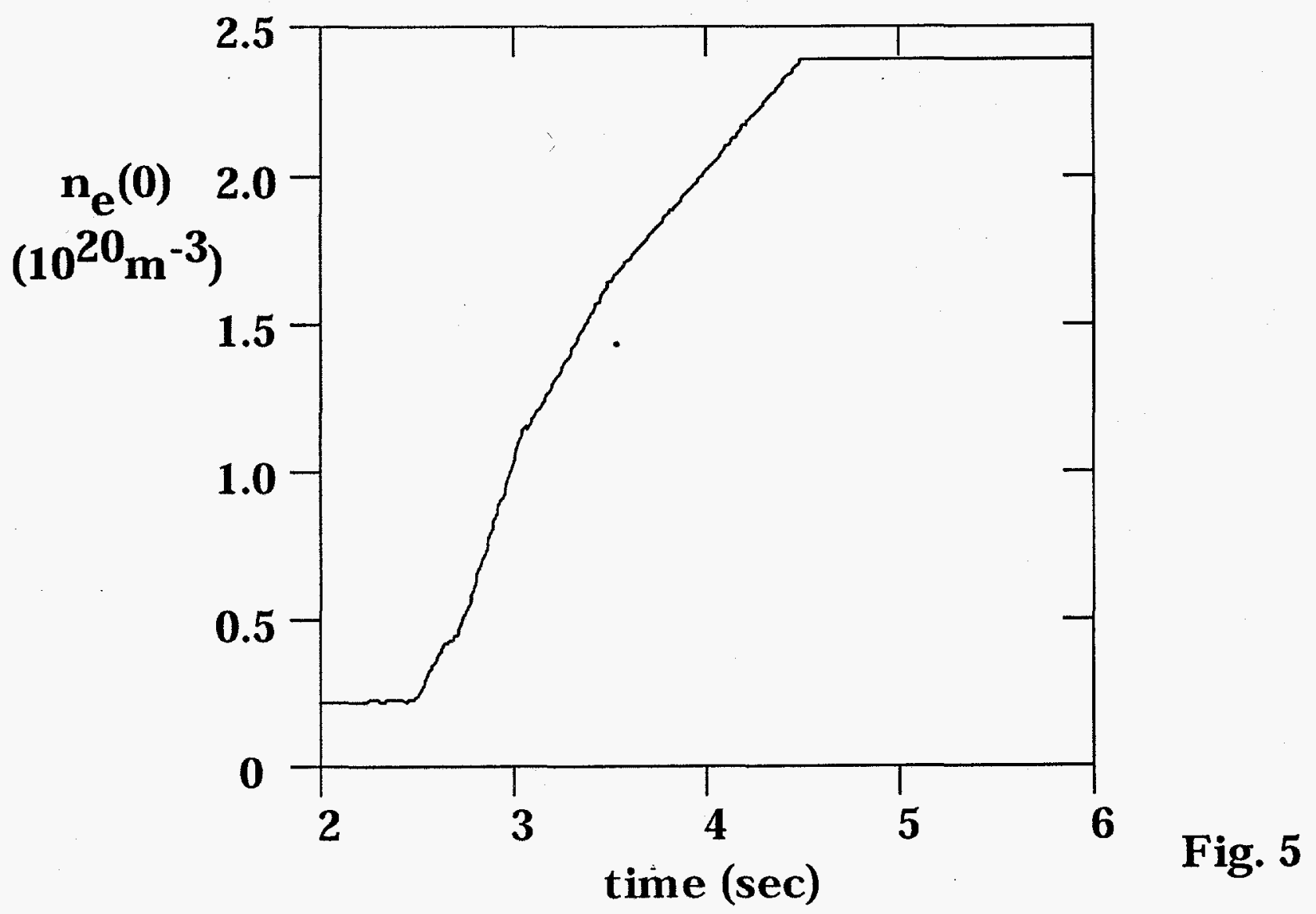



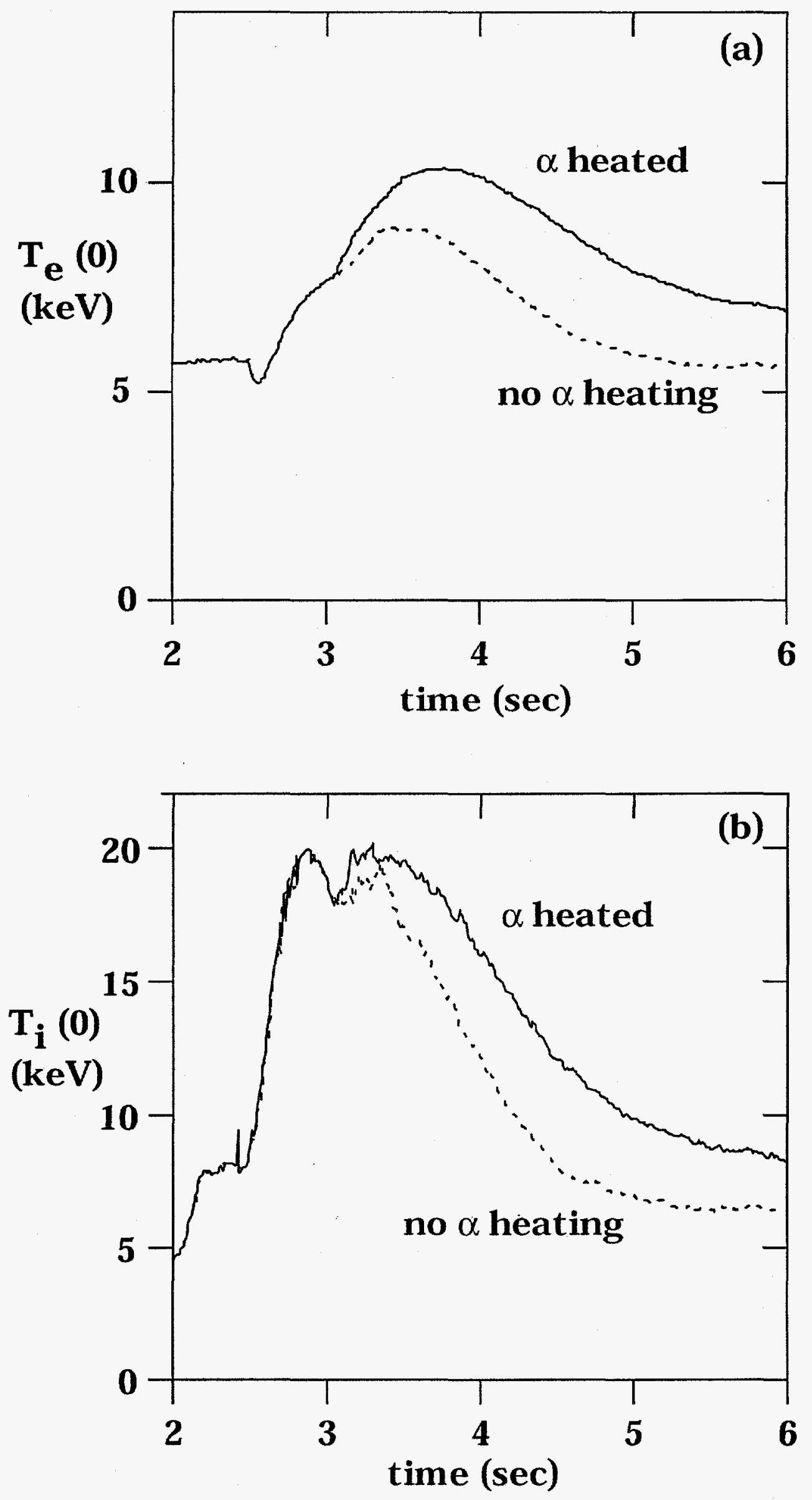

Fig. 6 


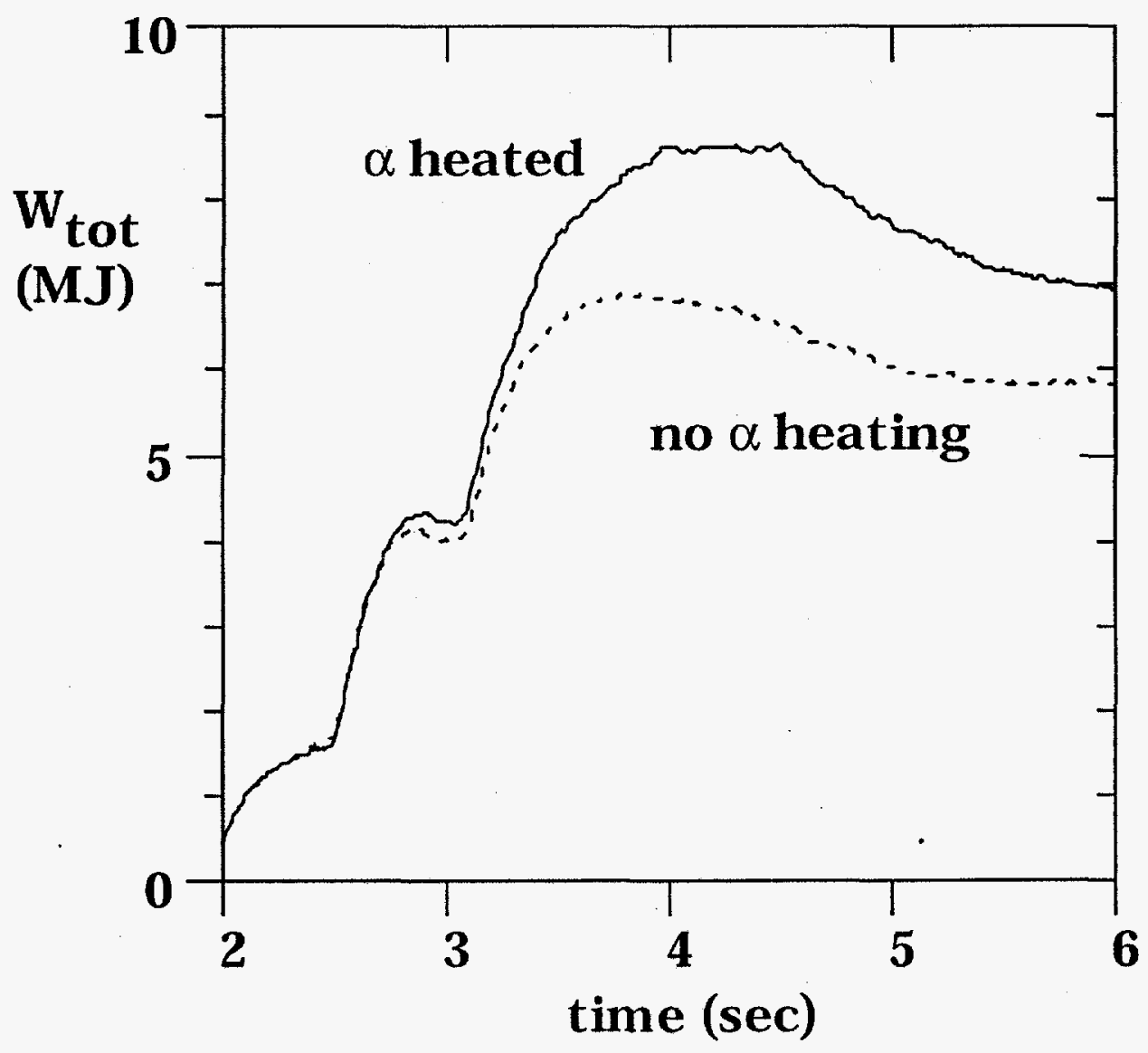

Fig. 7

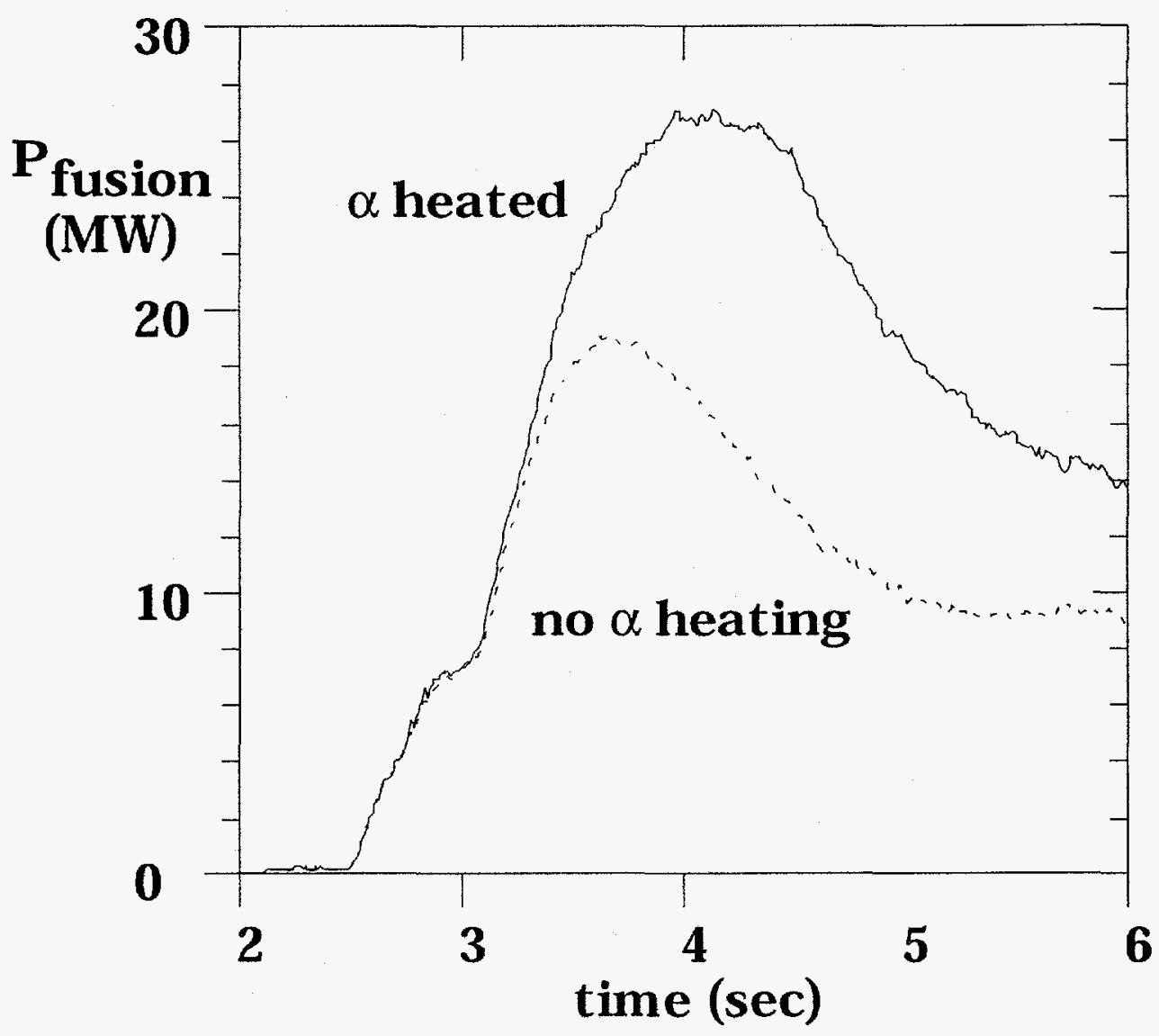

Fig. 8 

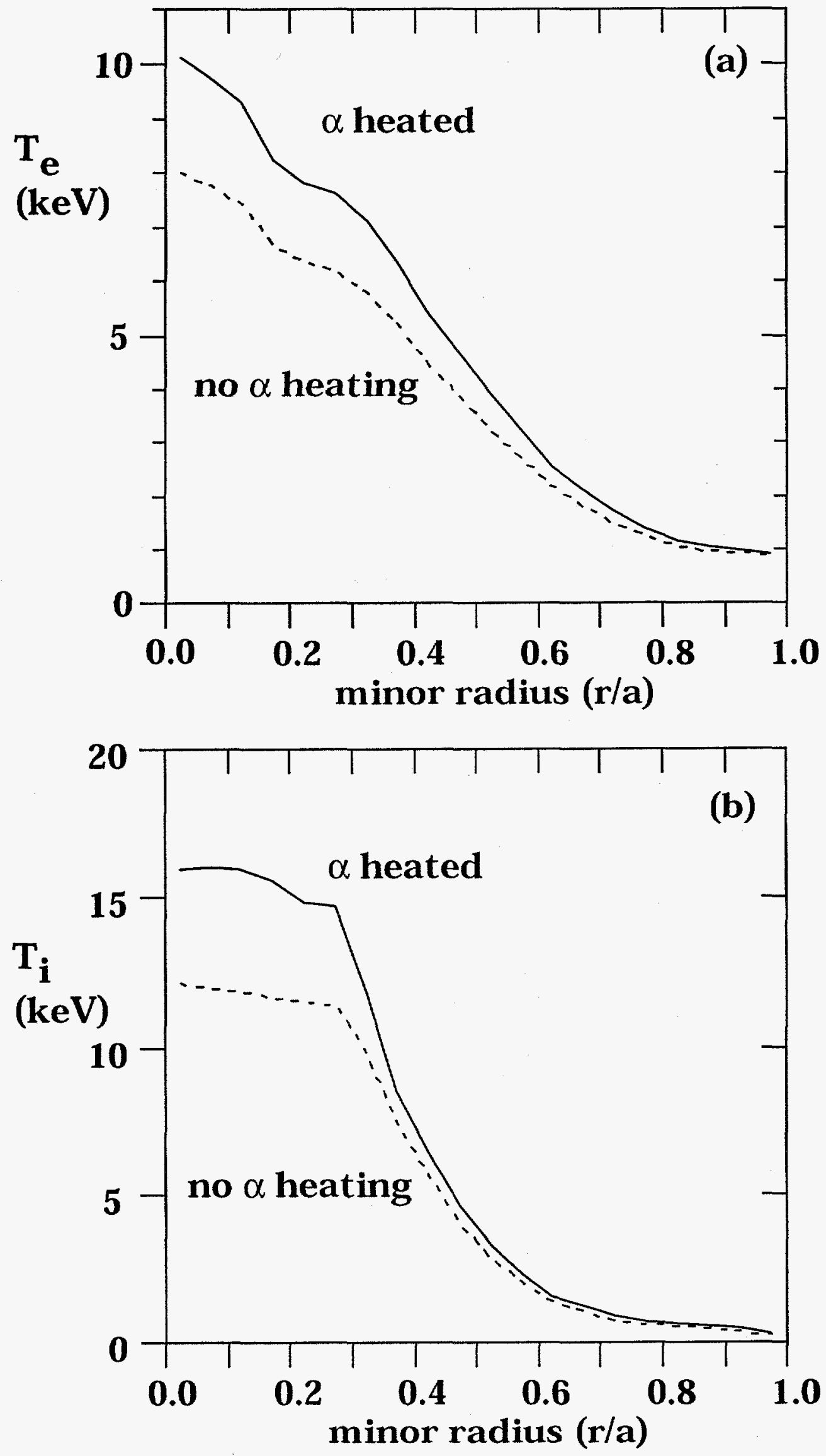

Fig. 9 